\title{
Sulu çözeltilerden nano kil (halosit) yüzeyine metilen mavisi adsorpsiyonu ve kinetiği
}

\author{
Aydın TÜRKYILMAZ* \\ Kastamonu Üniversitesi, Mühendislik Mimarlık Fakültesi, Çevre Mühendisliği Bölümü, \\ Kastamonu \\ Gelis Tarihi (Recived Date): 24.05.2018 \\ Kabul Tarihi (Accepted Date): 20.09.2018
}

\section{Özet}

Bu çalışmada sulu çözeltilerden halosit nano kil yüzeyine metilen mavisinin adsorpsiyonu $\mathrm{pH}$ ve sicakllk gibi parametreler kullanılarak incelendi. Adsorpsiyon prosesinin 24 saat içinde dengeye ulaştığı ve halosit nano kil yüzeyinde metilen mavisinin adsorplanmış miktarının artan $\mathrm{pH}$ ve sıcaklıkla arttı̆̆ bulundu. Deneysel veriler Langmuir ve Freundlich adsorpsiyon izotermleri kullanılarak analiz edildi ve adsorpsiyon verilerinin Langmuir izotermi ile oldukça iyi bir uyum gösterdiği belirlendi. Qmax;13.1 $\times 10^{5} \mathrm{~mol} / \mathrm{g}$ ve $K ; 44.25 \times 10^{-5} \mathrm{~L} / \mathrm{mol}$ olarak hesaplandl. Ayrica metilen mavisi için reaksiyon kinetiği deneyleri yapıldı. Reaksiyon kinetiğinin 2. Derece kinetiğe uyduğu bulundu.

Anahtar kelimeler: Halosit, metilen mavisi, adsorpsiyon, adsorpsiyon kinetiği.

\section{Methylene blue adsorptions and kinetics onto nano clay (halloysite) surface from aqueous solutions}

\begin{abstract}
In this study the adsorption of methylene blue dyes onto halloysite nano clay from aqueous solutions was searched using parameters for instance $\mathrm{pH}$ and temperature. Adsorption process was attained to the equilibrium included $24 \mathrm{~h}$. the adsorbed amount of methylene blue dyes on halloysite nano clay gone up with increasing $p H$ and temperature. The experimental data were analysed by Langmuir and Freundlich isotherms, and found that the isotherm data were match correlated by Langmuir isotherm. Qmax;13.1 $110^{5} \mathrm{~mol} / \mathrm{g}$ and $K ; 44.25 \times 10^{-5} \mathrm{~L} / \mathrm{mol}$ are calculated. In addition,
\end{abstract}

*Aydın TÜRKYILMAZ, aturkyilmaz@kastamonu.edu.tr, https://orcid.org/0000-0002-9379-9995 
reaction kinetics experiments were carried out for methylene blue. The reaction kinetic was found to have 2 st. degree kinetic.

Keywords: Halloysite, methylene blue, adsorption, adsorption kinetics.

\section{Giriş}

Su kirliliği, sanayi ve işletme atıklarının arıtılmadan alıcı ortamlara boşaltılması, tarımda kullanılan kirleticilerin sularla taşınması gibi nedenlerle gerçekleşmektedir. Çevre kirliliğini oluşturan sebeplerin başında sanayi atık suları gelmektedir. Canlılığın devamı için gerekli olan toprağın yapısına katılan sentetik maddeler toprak kirliliğine sebep olmaktadır ve dolaylı yollardan topraktan bitkilere geçen kirletici maddeler, besin zinciri yoluyla insana kadar ulaşmaktadır. Son 20 yılda sanayinin gelişmesi birçok sorunu da beraberinde getirmektedir.

Petrol, kömür madenleri, sentetik/kauçuk, gıda, tekstil, kağıt, selüloz ve metal işletmelerinden çevreye bırakılan atık maddeler çevre açısından önemli problemler oluşturmaktadır. Bu sebeple sulama ve içme suyu olarak kullanılacak suların endüstriyel kirlilik yükü bakımından dünyaca kabul edilen sınırlara indirgenmesi gerekmektedir. Yukarıda işaret edilen sahalardan en önemlisi su kirliliğidir. Çünkü bu kirleticiler zamanla yağmur ve kar gibi etkenlerle taşınarak suya geçmektedir. Suda bulunan kirleticiler; bitkiler, hayvanlar ve su ürünleri tarafından depo edilirler. Böylece insanlar beslenme ile birlikte belirli miktarlarda kirleticileri de alırlar. Bu nedenle zamanımızın en önemli konularından birisi, sanayileşmenin ve ülkemizdeki hızlı nüfus artışının ortaya çıkardığı çevre kirlenmesinin önlenmesi, ekonomik ve kesin çözümler üretmektir. Kirlenmiş çevreyi temizlemek ülke ekonomisi açısından oldukça pahalı ve kompleks tesisler gerektirdiğinden, çevremizin kirlenmesini önleyici tedbirler üzerine çalışmak daha da önem kazanmaktadır. Sulu ortamdan atıkların giderimi için çeşitli yöntemler kullanılmaktadır. Örneğin gümüş iyonlarının sulu çözeltilerden gideriminde kullanılan halosit nano killer gümüşün adsorpsiyonunda oldukça verimli olduğu bulunmuştur[1]. Mekanik özellikleri, mükemmel kimyasal stabilitesi, yüksek spesifik yüzey alanı, gözenekliliği ve yüksek adsorpsiyon kapasitesinden dolayı halosit pahalı karbon nano tüpleri için iyi bir alternatiftir[2].

$\mathrm{Bu}$ çalışmada silika türü bir adsorbent olan halosit nano kil organik boyar maddelerin gideriminde kullanılabilirliğinin incelenmesi amaçlanmaktadır. Bu amaçla halosit nano kil yüzeyinde metilen mavisinin adsorpsiyonu $\mathrm{pH}$ ve sicaklığın bir fonksiyonu olarak incelendi. Yapılan literatür araştırmaları sonucunda bu tür adsorbentin çok sınırlı olarak kullanıldığı görülmüşsür.

\section{Materyal ve metot}

\subsection{Materyal}

Deneylerde kullanılan halosit nano kil Aldrich marka, sentetik, yumuşak ve beyaz, bir kil türü olup nano boyuttadır. Yoğunluğu $2.62 \mathrm{~g} / \mathrm{cm}^{3}$ ve sertliği $1.5-2$ arasında olup, ideal bileşiminde \%21.76 silisyum, \%20.90 alüminyum ve \%1.56 hidrojen bulunmaktadır. Mineralojik formülü, $\mathrm{Al}_{2} \mathrm{O}_{3} \cdot 2 \mathrm{SiO}_{2} \cdot 4 \mathrm{H}_{2} \mathrm{O}$ "dir [3]. 
Metilen mavisi Carlo Erba firmasından temin edilmiştir. Molekül ağırlığı, 373.9 g/mol olup yapısı aşağıda verilmiştir [4].<smiles>CN(C)c1ccc2nc3ccc(=[N+](C)[O-])cc-3sc2c1</smiles>

pH ayarlaması için $\mathrm{HCl}$ ve $\mathrm{NaOH}$ kullanılmış olup bütün kimyasallar analitik saflıkta ve Merck firmasından temin edilmiştir. Örneklerin tartımları, Adam PW 214 model terazi; pH ölçümleri, Hanna HI 2211-02 model pH metre; ve UV/VIS ölçümleri; Hach Lange DR 6000 UV/VIS spektrofotometre kullanılarak gerçekleştirilmiştir.

\subsection{Metot}

Adsorpsiyon deneyleri belli konsantrasyondaki $50 \mathrm{~mL}$ sulu metilen mavisi çözeltisinin $0.1 \mathrm{~g}$ Halosit nano kil örneğinin kullanılmasıyla farklı pH ve sıcaklıklarda 24 saat 100 mL'lik polietilen kaplarda çalkalanması ile gerçekleştirilmiştir. Ön denemeler Halosit nano kil yüzeyinde metilen mavisi adsorpsiyonunun 24 saatte dengeye eriştiğini göstermiştir. Çalkalayıcı inkübatör ile sıcaklık sabit tutulmuştur. Deneylerde metilen mavisinin, $1 \times 10^{-2}$ ve $1 \times 10^{-3} \mathrm{~mol} / \mathrm{L}$ 'lik stok çözeltileri kullanılmıştır. Çözeltinin $\mathrm{pH}$ 's1, kombine elektrot ile donatılmış Hanna HI 2211-02 model pH metre kullanılmış, çözelti pH'sının ayarlanmasında ise $\mathrm{HCl}$ ve $\mathrm{NaOH}$ 'in sulu çözeltileri kullanılmıştır. Örneklerin ölçümünden önce pH-metrenin kalibrasyonu yapılarak doğrulanmıştır. Adsorpsiyon sürecinin sonunda çözelti 3500 rpm'de 30 dakika santrifüj edilmiştir. Çözelti fazından pipet ile $10 \mathrm{~mL}$ 'lik tüplere alınan örnekler değişik oranlarda distile su ile seyreltildikten sonra çözeltideki metilen mavisi konsantrasyonu Hach Lange DR 6000 UV/VIS spektrofotometre ile $663 \mathrm{~nm}$ dalga boyunda belirlenmiştir. Her seri deney için metilen mavisinin adsorplanmış miktarı, adsorpsiyondan önce ve sonraki çözeltideki konsantrasyonlarından hesaplanmış ve metilen mavisi içermeyen kör çözeltiler, deneylerin her bir serisi için kullanılmıştır. Halosit nano kilinin gram miktarı başına adsorplanmış metilen mavisinin miktarı aşağıdaki denklemden hesaplanmıştır.

$$
\mathrm{q}_{\mathrm{e}}=\left(\mathrm{C}_{0}-\mathrm{C}_{\mathrm{e}}\right) \frac{\mathrm{V}}{\mathrm{W}}
$$

Burada $\mathrm{q}_{\mathrm{e}}$, dengede halosit nano kil yüzeyinde adsorplanmış metilen mavisinin miktarı (mol/g); $\mathrm{C}_{0}$ ve $\mathrm{C}_{\mathrm{e}}$, sırasıyla adsorpsiyondan önce ve sonra çözeltideki metilen mavisi miktarı (mol/L); V, çözeltinin hacmi (L) ve W, halosit nano kilin gram miktarıdır [5]

Kinetik deneyleri için metilen mavisi kullanılmadan önce $110^{\circ}$ C'de 2 saat kurutulmuştur. Metilen mavisi çözeltisinin $2 \times 10^{-4} \mathrm{~mol} / \mathrm{L}$ 'lik stok çözeltisi saf su ile hazırlanmıştır. Hazırlanan çözelti $10 \mathrm{~g}$ Halosit nano kil ile 1 L'lik balona konulup istenen konsantrasyon, $\mathrm{pH}$ ve sıcaklıkta magnetik karıştırıcı ile 500 rpm karıştırma hızında 30 dakika reaksiyonun dengeye gelmesi beklenmiştir. Sonra uygun sürelerde çözeltiden pipet ile örnekler alınıp, 15 dakika $3000 \mathrm{rpm}$ de santrifüj edilmiştir. Daha sonra santrifüj edilen örnekler Hach Lange DR 6000 UV/VIS spektrofotometre ile 663 nm'de absorbansları ölçülmüştür. Reaksiyon kinetiği; 
1. Derece için;

$\ln \left(\mathrm{q}_{\mathrm{e}}-\mathrm{q}_{\mathrm{t}}\right)=\ln \mathrm{q}_{\mathrm{e}}-\mathrm{k}_{1} \mathrm{t}$

2. derece kinetik için ise:

$$
\frac{\mathrm{t}}{\mathrm{q}_{\mathrm{t}}}=\frac{1}{\mathrm{k}_{2} \mathrm{q}_{\mathrm{e}}^{2}}+\frac{1}{\mathrm{q}_{\mathrm{e}}}
$$

eşitlikleri ile hesaplanmıştır. Burada $\mathrm{q}_{\mathrm{e}}$ ve $\mathrm{q}_{\mathrm{t}}$ adsorplanan metilen mavisi miktarını (mol/g), t zaman (dak) $\mathrm{k}_{1}$ h1z sabiti $\left(\mathrm{dak}^{-1}\right), \mathrm{k}_{2} 2$. derece hız sabitini $\left(\mathrm{g} \mathrm{mol}^{-1} \mathrm{dak}^{-1}\right)$ ifade etmektedir [6].

\section{Bulgular}

Halosit nano kil yüzeyinde metilen mavisi adsorpsiyonu, $\mathrm{pH}$ ve sicaklığın bir fonksiyonu olarak incelenmiştir. Dengedeki halosit yüzeyinde adsorplanan metilen mavisi miktarları aşağıdaki kütle denkliği eşitliği kullanılarak hesaplanmıştır:

$$
\mathrm{q}_{\mathrm{e}}=\left(\mathrm{C}_{0}-\mathrm{C}_{\mathrm{e}}\right) \frac{\mathrm{V}}{\mathrm{W}}
$$

Burada $\mathrm{C}_{0}$ ve $\mathrm{C}_{\mathrm{e}}$, tekstil boyar maddesinin başlangıçtaki ve dengedeki sıvı faz derişimi (mol/L); V, boyar madde çözeltisinin hacmi (L); ve W, Halosit örneğinin kütlesidir (g) .

\subsection{Adsorpsiyon deneyleri}

\section{pH'nın etkisi}

Katı madde yüzeylerine metilen mavisinin adsorplanmış miktarını kontrol eden önemli faktörlerden birisi pH'dır. Boyar maddelerin adsorplanması, çoğu zaman adsorplanan $\mathrm{H}^{+} / \mathrm{OH}^{-}$miktarı ile belirlenmesine ve katı taneciğin elektrokinetik özelliklerine bağlıdır. Elektrokinetik davranış tanecik yüzeyindeki net yük ile belirlenmektedir [7]. 


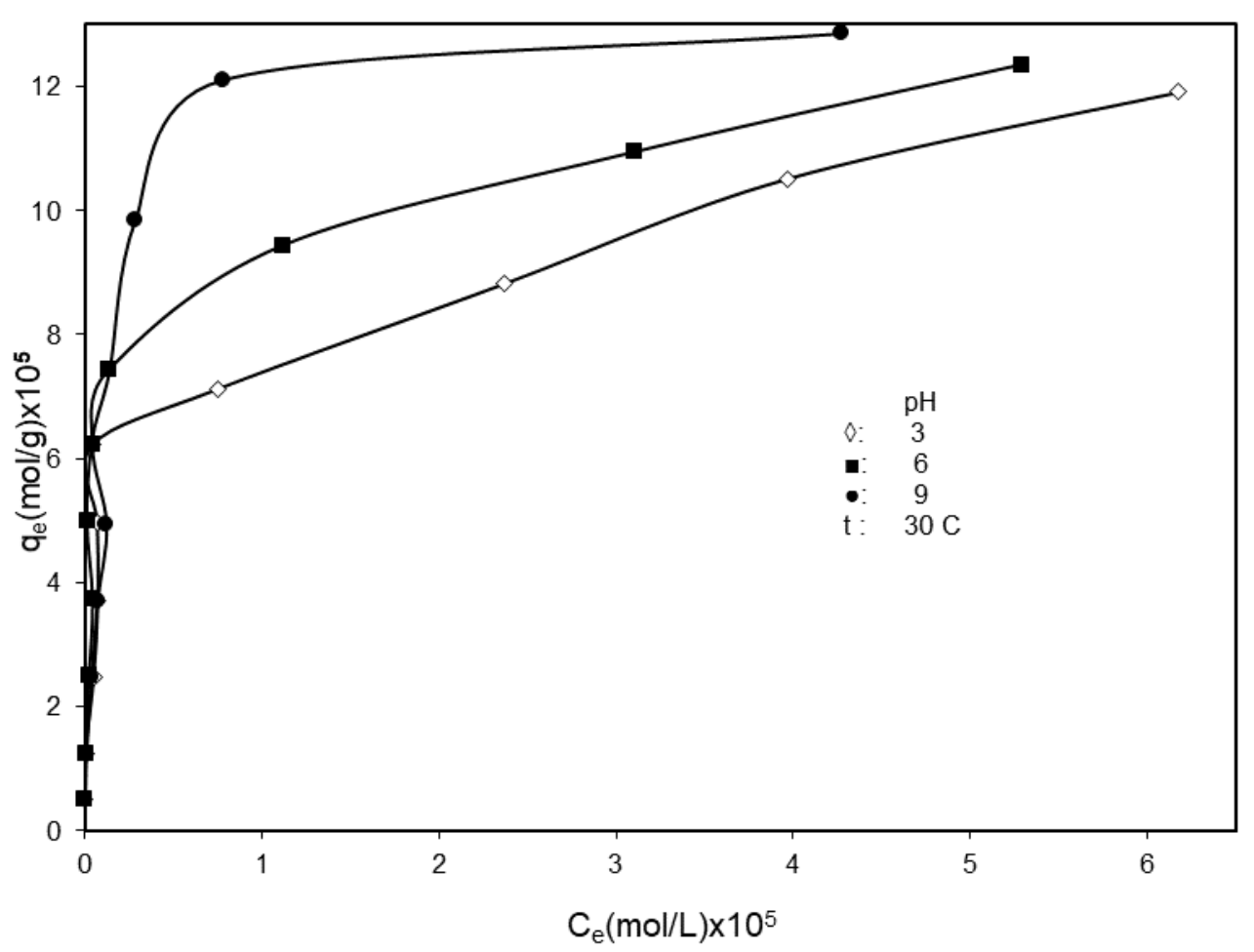

Şekil 1. Halosit nano kil yüzeyinde metilen mavisinin adsorpsiyonuna pH'nın etkisi.

Halosit nano kil yüzeyinde metilen mavisinin adsorpsiyonuna pH'nın etkisi pH 3, 6 ve 9 çözelti $\mathrm{pH}$ değerleri kullanılarak incelendi (Şekil 1). Bu şekilden görüldüğü gibi, metilen mavisinin adsorbent yüzeyinde adsorplanan miktarı artan çözelti pH'sı ile artmaktadır. Halosit nano kil adsorbent yüzeyi, negatif yüklü olduğu için aşağıdaki reaksiyonda görüldüğü gibi katyonik boya ile etkileşmesi kolay olacaktır.

$\mathrm{SO}^{-}+\mathrm{Dye}^{+}=\mathrm{SO}^{-} \mathrm{Dye}^{+}$

\section{Sicaklı̆̆ın etkisi}

Halosit nano kil yüzeyinde metilen mavisinin adsorpsiyonu üzerine sicaklığın etkisi 30$60{ }^{\circ} \mathrm{C}$ arasında incelenmiş ve deneysel sonuçlar Şekil 2.'de grafik edilmiştir. Şekilden de anlaşıldığı gibi sıcaklık artışıyla halosit yüzeyinde metilen mavisinin adsorplanan miktarının arttığı görülmektedir. Bunun nedeni artan sıcaklık ile beraber düşük sıcaklıklarda daha hareketsiz olan, hacimce büyük metilen mavisi moleküllerinin hareketindeki artmadır. Artan sıcaklıkla çok sayıda boyar madde molekülü halosit nano kil yüzeyindeki aktif noktalarla etkileşime girerek yeterli enerjiye sahip olmaya çalışacaklardır [8-9]. Halosit nano kil adsorpsiyon kapasitesinin artan sıcaklıkla artması entalpi değişiminin pozitif olmasını gerektirir. Bu durumda halosit nano kil yüzeyindeki metilen mavisinin adsorpsiyon prosesinin endotermik bir proses olduğu söylenebilir. 


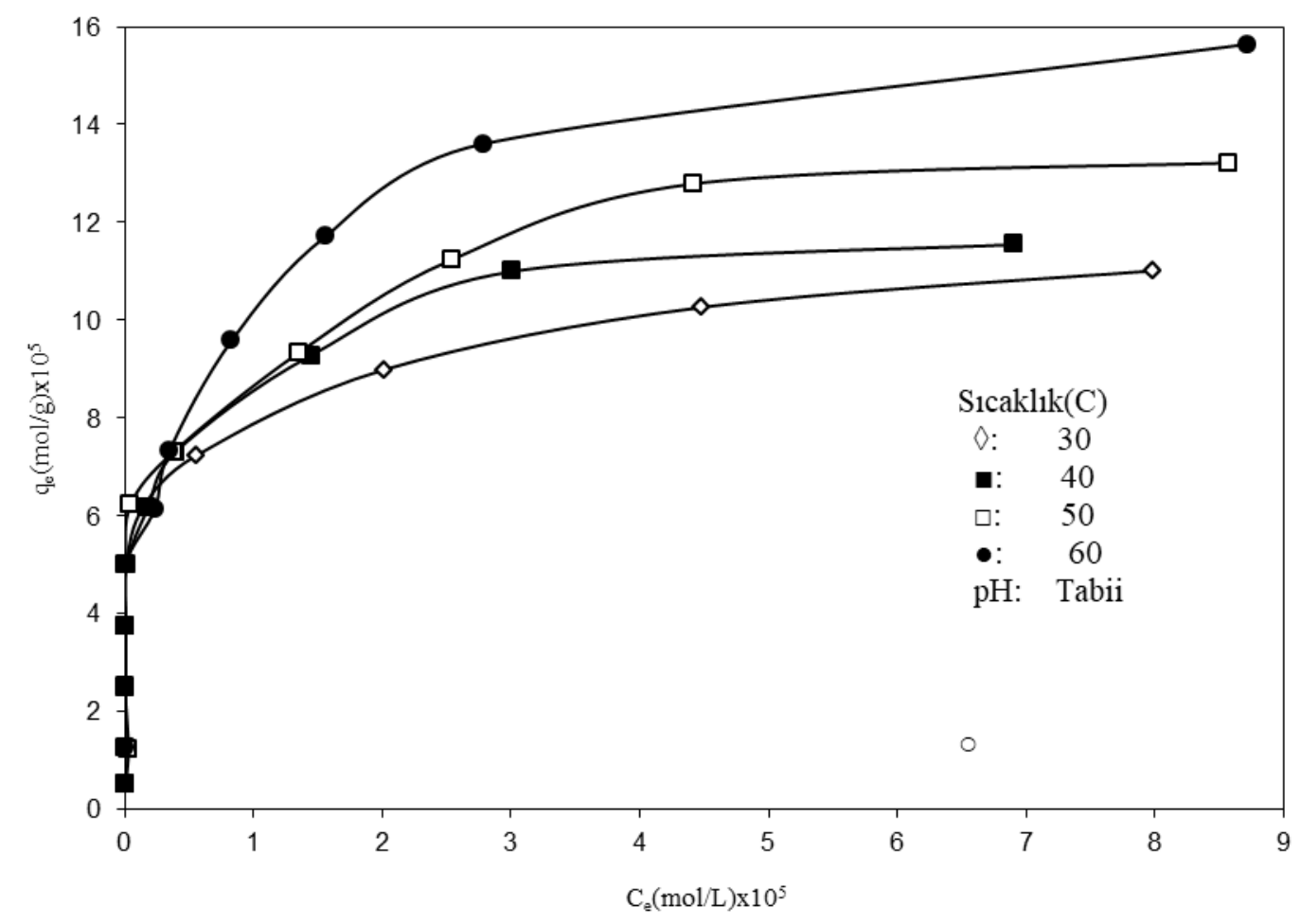

Şekil 2. Halosit nano kil yüzeyinde metilen mavisinin adsorpsiyonuna sicaklığın etkisi.

\subsection{Adsorpsiyon kinetiği}

Halosit nano kil yüzeyine metilen mavisinin adsorpsiyon kinetiği üzerine, karıştırma hızının, başlangıç konsantrasyonunun ve sıcaklığın etkisinin incelenmesi ile elde edilen deneysel veriler aşağıda açıklanmıştır.

\section{Karısturma hızının etkisi}

Halosit nano kil üzerine metilen mavisinin adsorpsiyon kinetiği 200, 300, $500 \mathrm{rpm}$ karıştırma hızlarında çalışılarak elde edilen sonuçlar Şekil 3'de ve Çizelge 1'de verilmektedir. Elde edilen sonuçlara göre adsorpsiyon hızının karıştırma hızının artışı ile arttığı gözlenmiştir.

\section{Konsantrasyonun etkisi}

Halosit nano kil üzerine metilen mavisinin adsorpsiyon kinetiğinin boyar madde konsantrasyonun artışı ile arttığı, bu artış Şekil 4'te ve deneysel sonuçların verildiği Çizelge 1 de görülmektedir. Bu artışın sebebi; adsorbent yüzeyinde aktif noktaların adsorplama kapasitelerinin boyar madde derişimi ile orantılı olarak dolması ve bütün aktif noktaların dolması ile reaksiyonun dengeye gelmesi ile açıklanabilir.

\section{Sıcaklı̆̆ın etkisi}

Sıcaklığın bütün reaksiyonların hız üzerine olan etkisi adsorpsiyon için adsorbent yüzeyinde bulunan aktif noktaların artan sıcaklık ile birlikte genişleyerek boyar maddenin daha fazla adsorplanmasını sağlamaktadır. Şekil 5 te görüldüğü gibi artan sicaklık ile birlikte reaksiyon hızı da artmaktadır. 


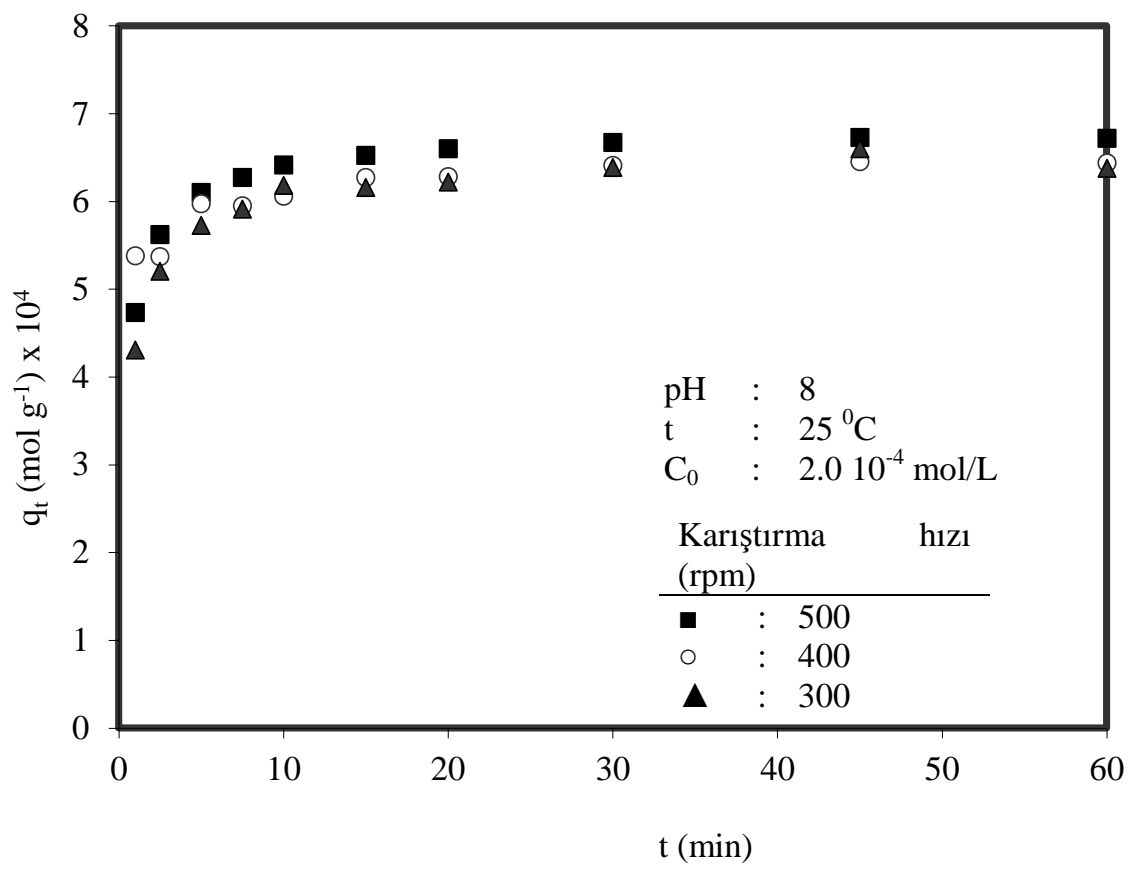

Şekil 3. Halosit nano kil yüzeyinde metilen mavisinin adsorpsiyonu üzerine karıştırma hızının etkisi.

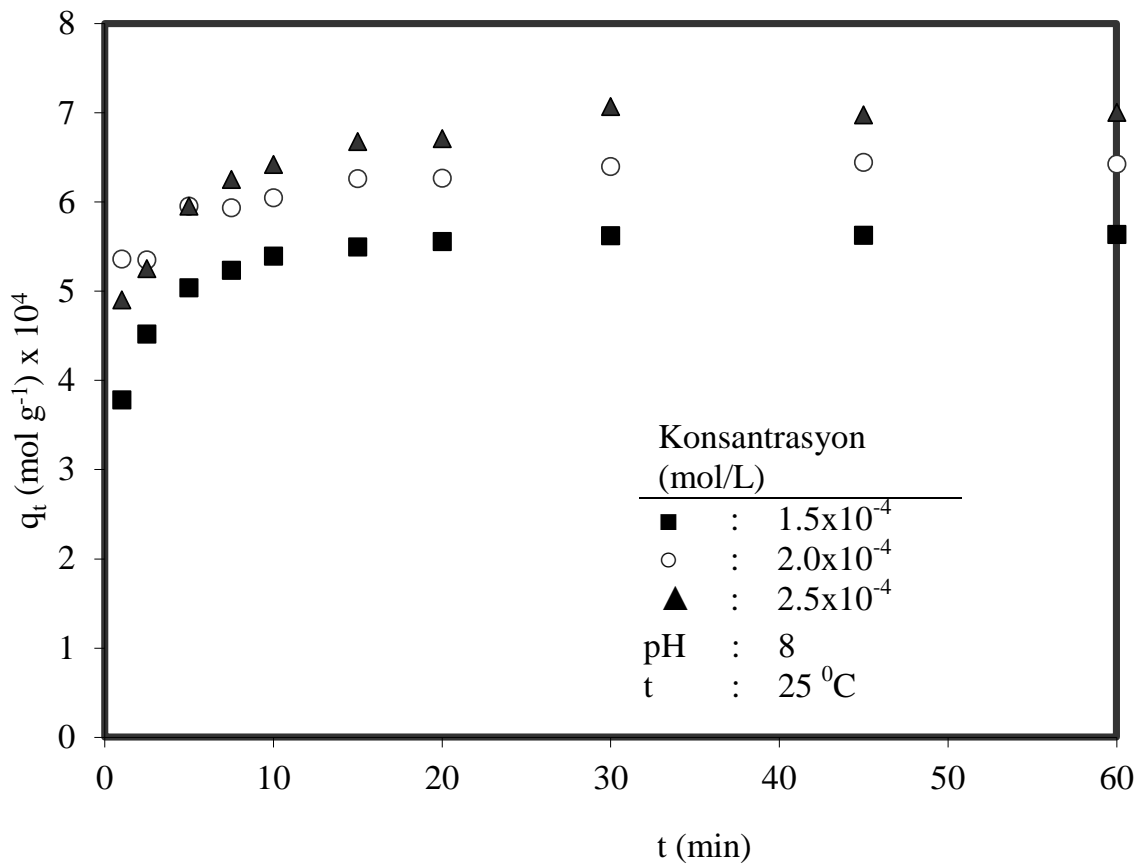

Şekil 4. Halosit nano kil yüzeyinde metilen mavisinin adsorpsiyonu üzerine konsatrasyonun etkisi. 


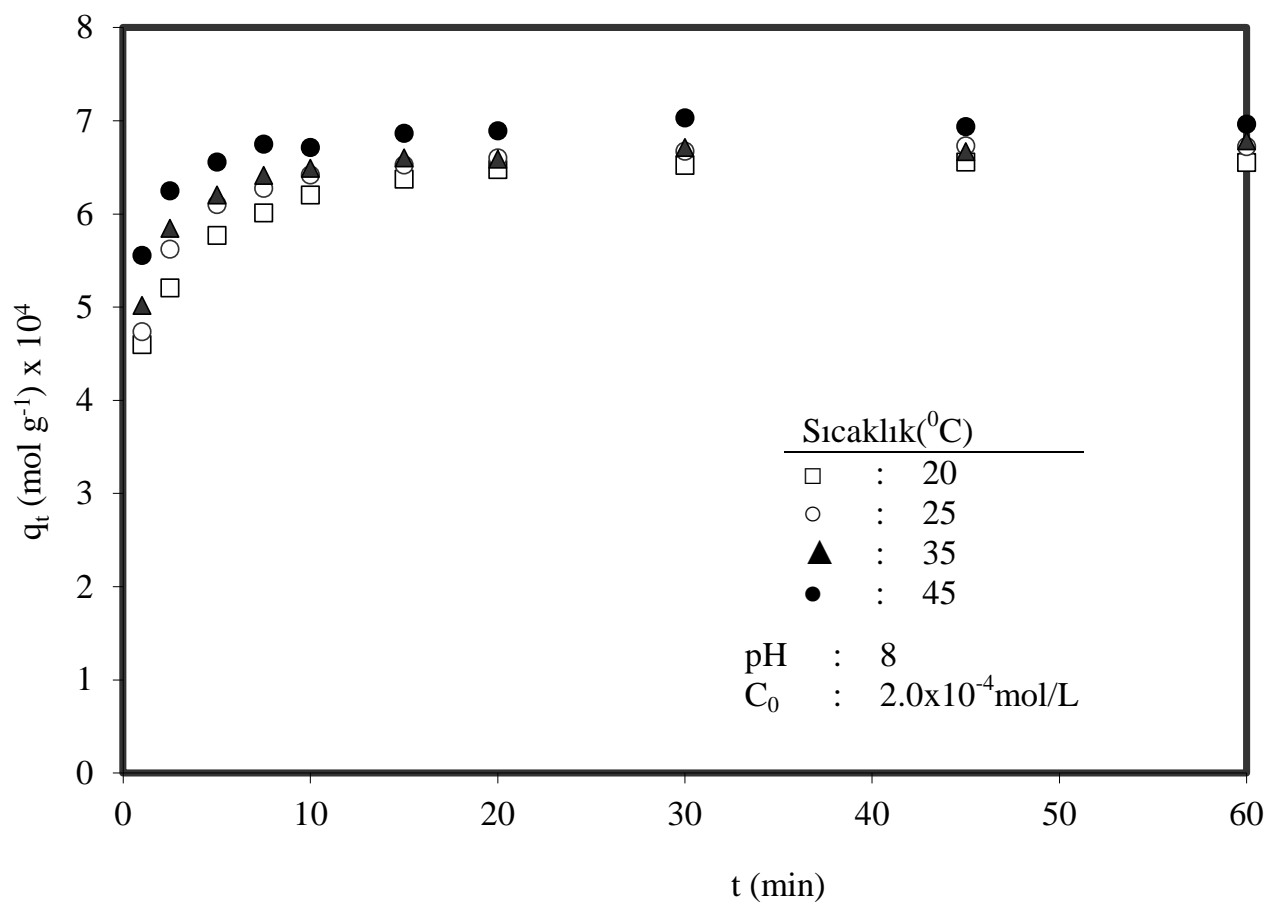

Şekil 5. Halosit nano kil yüzeyinde metilen mavisinin adsorpsiyonu üzerine sıcaklığın etkisi.

Çizelge 1. Halosit nano kil yüzeyinde metilen mavisi adsorpsiyonu için hesaplanan kinetik parametreler.

\begin{tabular}{|c|c|c|c|c|c|c|c|c|c|}
\hline \multicolumn{4}{|c|}{ Parametreler } & \multicolumn{5}{|c|}{ Kinetik modeller } & \multirow{3}{*}{$\begin{array}{c}\mathrm{t}_{1 / 2} \\
\text { (dak) }\end{array}$} \\
\hline \multirow[b]{2}{*}{$\begin{array}{c}\mathrm{t} \\
\left({ }^{0} \mathrm{C}\right)\end{array}$} & \multirow[b]{2}{*}{$\begin{array}{c}{\left[\mathrm{C}_{0}\right]} \\
(\mathrm{mol} / \mathrm{L}) \\
\times 10^{4}\end{array}$} & \multirow[b]{2}{*}{$\mathrm{pH}$} & \multirow[b]{2}{*}{$\begin{array}{c}\text { Karıştırma } \\
\text { hızı } \\
\text { (rpm) }\end{array}$} & \multirow[b]{2}{*}{$\begin{array}{c}\text { Birinci } \\
\text { derece } \\
\mathrm{R}^{2}\end{array}$} & \multicolumn{4}{|c|}{ İkinci derece } & \\
\hline & & & & & $\begin{array}{c}\mathrm{q}_{\text {e(hesap) }} \\
(\mathrm{mol} / \mathrm{g}) \\
\times 10^{5}\end{array}$ & $\begin{array}{c}\mathrm{q}_{\text {(exp) }} \\
(\mathrm{mol} / \mathrm{g}) \\
\mathrm{x} 10^{5}\end{array}$ & $\begin{array}{c}\mathrm{k}_{2} \\
\text { (g/mol.dak) }\end{array}$ & $\mathrm{R}^{2}$ & \\
\hline 20 & 2.0 & 8 & 500 & 0.962 & 0.65 & 0.68 & 2.646 & 0.998 & 3.998 \\
\hline 25 & 2.0 & 8 & 500 & 0.970 & 0.67 & 0.69 & 2.479 & 0.998 & 3.624 \\
\hline 35 & 2.0 & 8 & 500 & 0.961 & 0.69 & 0.68 & 9.458 & 0.998 & 11.334 \\
\hline 45 & 2.0 & 8 & 500 & 0.970 & 0.69 & 0.70 & 8.210 & 0.999 & 12.170 \\
\hline 25 & 2.0 & 8 & 300 & 0.975 & 0.66 & 0.66 & 3.890 & 0.998 & 3.415 \\
\hline 25 & 2.0 & 8 & 400 & 0.981 & 0.66 & 0.66 & 3.081 & 0.998 & 3.670 \\
\hline 25 & 1.5 & 8 & 500 & 0.981 & 0.60 & 0.57 & 4.132 & 0.998 & 4.612 \\
\hline 25 & 2.5 & 8 & 500 & 0.960 & 0.72 & 0.73 & 4.270 & 0.999 & 5.543 \\
\hline 25 & 2.0 & 8 & 500 & 0.938 & 0.65 & 0.65 & 4.250 & 0.999 & 6.034 \\
\hline 25 & 2.0 & 8 & 500 & 0.908 & 0.63 & 0.63 & 4.350 & 0.999 & 6.572 \\
\hline
\end{tabular}




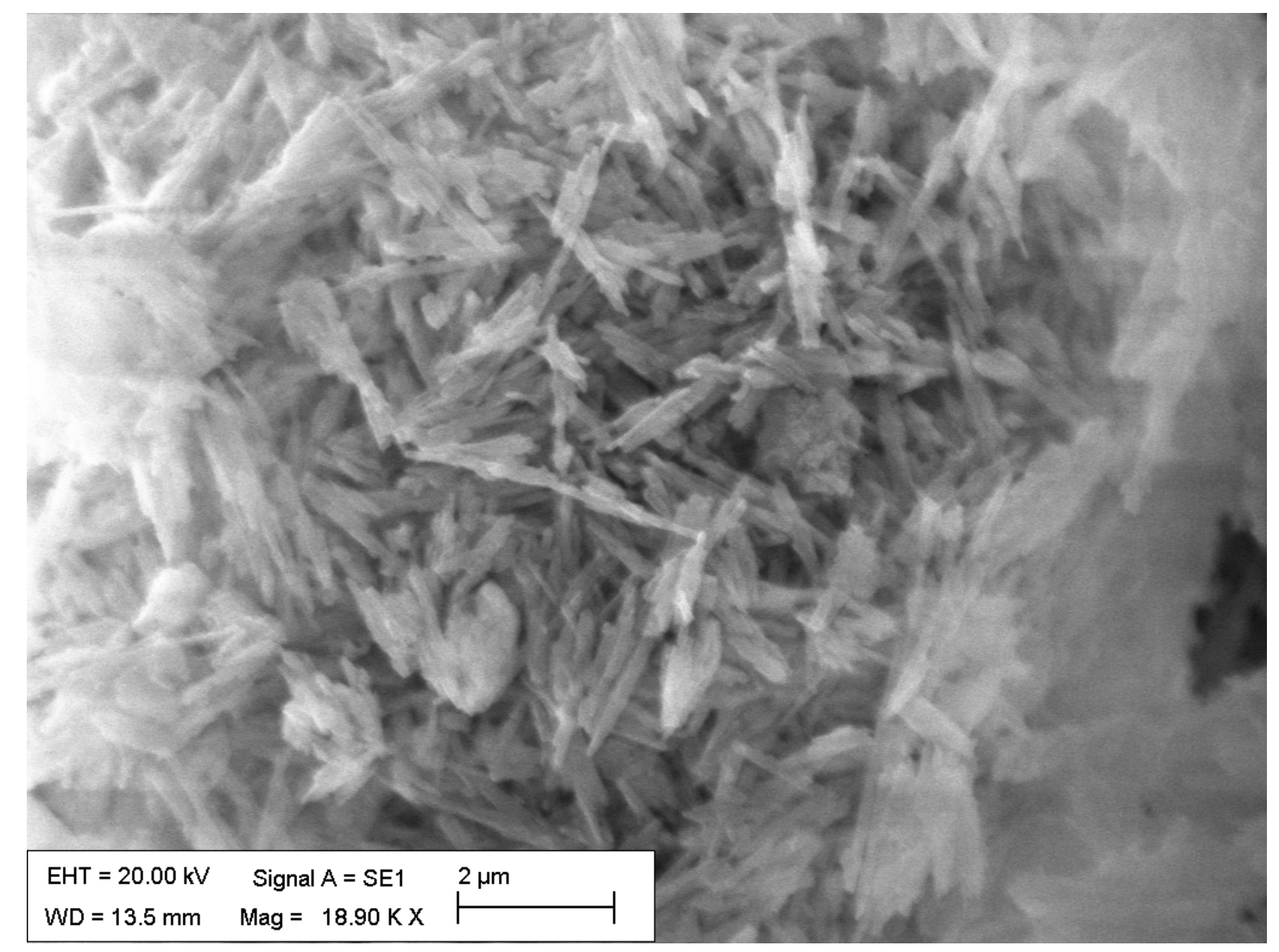

Şekil 6. Halosit nano kil SEM görüntüsü.

\section{Adsorpsiyon izotermleri}

Sabit sıcaklıkta adsorbent yüzeyinde adsorplanmış adsorbatın dengede miktarı ile adsorbatın çözelti fazındaki konsantrasyonu arasındaki ilişkiyi gösteren bağıntılara veya eğrilere adsorpsiyon izotermleri adı verilir. Adsorpsiyon izotermi hem teorik ve hem de pratik açıdan çok önemlidir. Bu çalışmada Freundlich ve Langmuir adsorpsiyon izotermleri deneysel verileri analiz etmek için kullanıldı. İzoterm eşitliklerinin deneysel verilere uygulanabilirliği korelasyon katsayıları kullanılarak değerlendirildi[3].

\subsection{Freundlich izotermi}

Freundlich izotermi deneysel bir eşitliktir aynı zamanda düşük konsantrasyonlar için iyi sonuçlar vermektedir. Bu eşitlik logaritmik formda aşağıdaki gibi verilir [10]:

$\operatorname{lnq}_{\mathrm{e}}=\ln \mathrm{K}_{\mathrm{F}}+\frac{1}{\mathrm{n}} \ln \mathrm{C}_{\mathrm{e}}$

Freundlich sabiti olan $n$, adsorpsiyon yoğunluğunun veya yüzey heterojenitesinin bir ölçüsüdür. Deneysel veriler Freundlich izotermi ile iyi bir uyum sağliyorsa $1 / n$ değerleri, 0 ile 1 aralığında değişir ve bu değer ne kadar fazla sıfıra yaklaşırsa yüzey heterojenitesi o kadar artar [5]. Yukarıdaki (6) denklemine göre $\operatorname{lnq}_{\mathrm{e}}$ 'nin $\operatorname{lnC} \mathrm{C}_{\mathrm{e}}$ ' ye karşı grafiği çizildiğinde doğrunun eğim ve kesim noktası değerinden izoterm sabitleri $\mathrm{K}_{\mathrm{F}}$ ve n belirlenebilmektedir[3]. Çizelge 2. farklı $\mathrm{pH}$ ve sıcaklıklarda halosit nano kil yüzeyine metilen mavisinin adsorpsiyonu için hesaplanmış Freundlich izotermlerine ait hesaplamaları ifade etmektedir. Adsorpsiyon verilerinin Freundlich izotermine 
uyduğunu belirlemek için regrasyon katsayısının 1'e yakın değerde olması gerekir. Sonuçlar incelendiğinde, elde edilen eğrilerden hesaplanan regrasyon katsayılarının 0.81-0.56 aralığında olması adsorpsiyon verilerinin Freundlich izotermi ile iyi bir şekilde örtüşmediği görülmektedir.

\subsection{Langmuir izotermi}

Langmuir izotermi, birden fazla sayıda birbirine benzeyen noktalardan meydana gelen bir yüzeydeki tek tabaka adsorpsiyonunu açıklamakta kullanılan izotermdir. Bu model kat1 yüzeyindeki adsorpsiyon işleminde enerjinin sabit olduğunu ve adsorbent yüzeyindeki adsorplanan moleküllerin hareketinin mümkün olmadığını kabul etmektedir. Langmuir izotermi aşağıdaki eşitlikle verilebilir [9]:

$$
\frac{\mathrm{C}_{\mathrm{e}}}{\mathrm{q}_{\mathrm{e}}}=\frac{1}{\mathrm{q}_{\mathrm{m}} \mathrm{K}}+\frac{\mathrm{C}_{\mathrm{e}}}{\mathrm{q}_{\mathrm{m}}}
$$

$\mathrm{C}_{\mathrm{e}} / \mathrm{q}_{\mathrm{e}}$ 'nin $\mathrm{C}_{\mathrm{e}}$ ' ye karşı çizilen eğrinin, eğimi $1 / \mathrm{q}_{\mathrm{m}}$ ve ordinatın kesim noktası $1 / \mathrm{q}_{\mathrm{m}} \mathrm{K}$ olan doğrusal bir eğim verecektir. [11,12,13,14]. Veriler, en küçük kareler metodu ile hesaplanmış ve ilgili korelasyon sabitleri ( $\mathrm{R}^{2}$ değerleri) Çizelge 2'de verilmiştir. Çizelge 2 'den görüldüğü gibi deneysel verilerin Langmuir izotermine uygulanmasıyla elde edilen doğruların regrasyon katsayısı 0,99-0,990 arasında değişmektedir. Bu sonuçlar deneysel verilerin Langmuir izoterminin deneysel verilerle uyumlu olduğunu göstermektedir. Langmuir izoterminin deneysel sonuçlar ile uyum göstermesi, halosit nano kil yüzeyindeki aktif noktaların homojen dağılmasından kaynaklanmaktadır çünkü Langmuir izotermi, yüzeyin homojen dağılımlı olduğunu kabul etmektedir[15,16]. Halosit nano kil yüzeyinde metilen mavisi adsorpsiyonuna $\mathrm{pH}$ ve sıcaklığın etkilerini gösteren Şekil 1 ve Şekil 2'deki grafiklerin eğim ve kesim noktası değerlerinden izoterm parametreleri olan $\mathrm{K}$ ve $\mathrm{q}_{\mathrm{m}}$ sabitleri hesaplanmış ve Çizelge 2'de verilmiştir.

Çizelge 2. Halosit nano kil yüzeyinde metilen mavisi adsorpsiyonu için hesaplanan izoterm parametreleri.

\begin{tabular}{|c|c|c|c|c|c|c|}
\hline \multicolumn{2}{|c|}{ Parametreler } & \multicolumn{4}{|c|}{ Langmuir izotermi } & \multirow{2}{*}{$\begin{array}{c}\begin{array}{c}\text { Freundlich } \\
\text { izotermi }\end{array} \\
\mathrm{R}^{2}\end{array}$} \\
\hline $\begin{array}{c}\text { Sicaklık } \\
\left({ }^{\circ} \mathrm{C}\right)\end{array}$ & $\mathrm{pH}$ & $\begin{array}{c}\mathrm{q}_{\mathrm{m}}(\mathrm{mol} / \mathrm{g}) \\
\times 10^{5} \\
\end{array}$ & $\begin{array}{c}\mathrm{K}(\mathrm{L} / \mathrm{mol}) \\
\mathrm{x} 10^{-5}\end{array}$ & $\mathrm{R}^{2}$ & $\mathrm{R}_{\mathrm{L}}$ & \\
\hline 30 & Doğal & 11 & 9.17 & 0.996 & $0.9-0.030$ & 0.81 \\
\hline 40 & Doğal & 12 & 10.3 & 0.997 & $0.7-0.037$ & 0.72 \\
\hline 50 & Doğal & 13 & 7.50 & 0.995 & $0.7-0.01$ & 0.56 \\
\hline 60 & Doğal & 16 & 4.80 & 0.993 & $0.4-0.09$ & 0.78 \\
\hline 30 & 3 & 11.5 & 11.70 & 0.99 & $0.9-0.03$ & 0.86 \\
\hline 30 & 6 & 12.1 & 44.25 & 0.998 & $0.9-0.03$ & 0.75 \\
\hline 30 & 9 & 13.2 & 19.92 & 0.998 & $0.8-0.05$ & 0.74 \\
\hline
\end{tabular}

\section{Sonuçlar}

$\mathrm{Bu}$ çalışmada halosit nano kil yüzeyine metilen mavisinin adsorpsiyonu $\mathrm{pH}$ ve sıcaklığın bir değişkeni olarak incelenmiş ve elde edilen sonuçlar aşağıda özetlenmiştir: 
1. Halosit nano kil yüzeyine metilen mavisinin adsorpsiyonunun $\operatorname{artan} \mathrm{pH}$ ve sicaklıkla arttığı,

2. Adsorpsiyon sürecinin endotermik olduğu,

3. Deneysel sonuçların Langmuir adsorpsiyon izotermine uyduğunu,

4. Adsorpsiyon prosesinde halosit ve metilen mavisi arasındaki etkileşimlerin fiziksel olduğu,

5. Reaksiyon kinetiğinin 2. derece kinetik ile uyumlu olduğu,

6. Halosit nanokilin yüzeyi iğnemsi yapıda olup bu durum kilin yüzey morfolojisinin incelenmesi için kullanılan SEM görüntülerinde (şekil 6) görülmektedir. Ayrıca yapının yüzeyi incelendiğinde gözenekli bir yapı olduğu,

7. Halosit nano kilin SEM görüntüsü incelendiğinde, adsorpsiyon için bir çok aktif noktanın olduğu,

8. Yapılan çalışma ile sulu çözeltilerden katyonik boyar maddelerin gideriminde halosit nano kilinin kullanılabileceği gösterilmiştir.

\section{Teşekkür}

$\mathrm{Bu}$ çalışma Kastamonu Üniversitesi Bilimsel Araştırma Projeleri Koordinatörlüğü tarafından desteklenmiştir. Proje Numarası:' KÜBAP-01 2016-29”

\section{Kaynaklar}

[1] Jing, Q. X., Cha1, L. Y, Huang, X. D., Tang, C.J., Guo, H.,Wang, W., Behavior of ammonium adsorption by clay mineral halloysite, Transactions of Nonferrous Metals Society of China 27,7, 1627-1635 (2017).

[2] Szczepanik, B., Słomkiewicz, P, Garnuszek, M., Czech, K., Adsorption of chloroanilines from aqueous solutions on the modified halloysite, Applied Clay Science, 101, 260-264 (2014).

[3] Mutlu, S., Halosit/poli(etilen glikol)-blok-poli(propilen glikol)-blok-poli(etilen glikol) nanokompozitlerinin sentezi ve karakterizasyonu, Yüksek Lisans Tezi, Balıkesir Üniversitesi Fen Bilimleri Enstitüsü, Balıkesir, (2010).

[4] Deng, H., Yang, L., Tao, G. ve Dai, J., Preparation and characterization of activated carbon from cotton stalk by microwave assisted chemical activationApplication in methylene blue adsorption from aqueous solution, Journal of Hazardous Materials, 166,2-3,1514-1521 (2009).

[5] Doğan, M., Sulu ortamda perlitin yüzey yükünün ve adsorpsiyon özelliklerinin incelenmesi, Doktora Tezi, Balıkesir Üniversitesi Fen Bilimleri Enstitüsü, Balıkesir, (2001).

[6] Doğan, M., and Alkan, M., Adsorption of copper(II) onto perlite Journal of Colloid and Interface Science, 243, 2 (2001).

[7] Huang, C.P., in M.A. Anderson and A.J. Rubin, Eds., p. 181, Ann Arbor, MI, (1981).

[8] Doğan, M., and Alkan, M., Chemosphere. 50, 517-528 (2003).

[9] Alkan, M., Demirbaş, O., and Dogan, M., Adsorption kinetics and thermodynamics of an anionic dye onto sepiolite, Microporous and mesoporous materials 101, 3, 388-396 (2007). 
[10] Doğan, M., Alkan, M., and Onganer, Y., Water, Air and Soil Pollution. 120, 229-248 (2000).

[11] Attard, G., and Barnes, C., Surfaces. 1-36, Oxford Science Publications, England, Oxford, (1998).

[12] Doğan, M., Sulu ortamda perlitin yüzey yükünün ve adsorpsiyon özelliklerinin incelenmesi, Doktora Tezi, Balıkesir Üniversitesi Fen Bilimleri Enstitüsü, Balıkesir, (2001).

[13] Rubin, A.J., and Mercer, D.L., in "Adsorption of Inorganic Solid-Liquid Interfaces" (M.A. Anderson and A.J. Rubin, Eds.), pp. 295-348, Ann Arbor, MI. (1981).

[14] Sarıkaya, Y., Fizikokimya ve problem çözümleri, Gazi Kitapevi, Ankara (1997).

[15] Fenol, P., and Martin Vivaldi, J.L., Anales de quimica 64,7782 (1968).

[16] Gonzàlez-Pradas, E., Villafranca-Sànchez, M., Valverde-Garcìa, A., and Socias-Viciana, M., J. Chem. Tech. Biotechnol. 42, 105 (1988). 